\title{
Fiscal policy coordination in monetary unions
}

\author{
Josef Schroth \\ Bank of Canada ${ }^{1}$
}

November 3, 2012

The paper studies the design of optimal fiscal rules for members of a monetary union when there are privately observed shocks to countries' social cost of domestic taxation. First, I show that optimal fiscal rules prescribe policy coordination in the sense of domestic taxation efforts that are positively correlated across member countries. In particular, coordination achieves higher ex-ante joint welfare than any fixed upper bound on domestic deficits. Second, I show that a history of asymmetric domestic taxation efforts leads to tighter policy coordination in the sense of an emergence of retaliatory fiscal policies. As a result, past disagreement leads to an increase in expected domestic deficits across the monetary union.

\section{Introduction}

In the aftermath of the 2008-2010 economic downturn, fiscal policies of some European Union member states proved to be unsustainable. Specifically, deteriorating fiscal conditions in a member country may limit its role as a net-contributor, reduce the value of its foreign-held public debt, or lead to a monetization of its fiscal deficit. Out of the presence of

\footnotetext{
${ }^{1}$ All expressed views are my own and not those of the Bank of Canada.
} 
these negative external effects arises the need to design fiscal rules that aim at allowing domestic fiscal policy to respond to domestic economic conditions while limiting inefficiently high budget deficits. It is clear, however, that the design of fiscal rules should address possible incentives of member countries to misrepresent domestic economic conditions. For example, in the case of the European monetary union (Eurozone), the Stability and Growth Pact stipulates an upper bound on budget deficits by Eurozone members. This fiscal rule, while having the benefit of dealing with informational asymmetries in an appropriate way, suffered an early death (Eichengreen, 2005) and has yet not been replaced. How to design fiscal rules that achieve a higher degree of flexibility while still limiting inefficiently high budget deficits seems to be an open question at this point. The contribution of this paper is address this question by fully analyzing a to my knowledge novel mechanism design problem and by using the results to characterize optimal fiscal rules for members of a monetary union.

In the paper, I build a model of a monetary union where negative external effects take the form of unsustainable member country budget deficits. The monetary authority can balance a country's budget by levying an inflation tax if conventional forms of taxation are deemed too costly. ${ }^{2}$ It is assumed that use of the inflation tax can be welfare increasing at times such that fiscal rules do not generally rule out the use of an inflation tax. The model allows for two countries and two types of agents in each country, workers and investors. Only workers can be taxed by the domestic government and only investors hold currency. ${ }^{3}$ Policy makers in each country take this environment as given and maximize a (domestic) weighted welfare measure. It is assumed that policy makers privately observe the relative

\footnotetext{
${ }^{2}$ I use the terms budget deficit and inflation tax interchangeably. It makes sense to think of asset markets as being integrated across the monetary union in the sense of an inflation tax affecting all countries similarly. Similar, if holdings of public debt are well diversified across the monetary union then a (partial) sovereign default can be seen as equivalent to an inflation tax (agents holding public debt are the same holding currency).

${ }^{3}$ This assumption does not restrict generality too much since taxes (both conventional and inflation taxes) are levied as lump sums. The idea is that investor income is mobile and must thus be taxed uniformly across the monetary union. In the paper, I call this tax on investors an inflation tax.
} 
welfare weight attached to workers. These weights are stochastic and are meant to capture that ex-ante identical countries may exhibit differentiated domestic conditions ex post. The respective weights, or domestic conditions, can be interpreted as political pressure from workers relative to investors or as the deadweight cost of taxing workers.

Due to the presence of this informational asymmetry, fiscal rules need to be designed in a way as to discourage policy makers from misrepresenting domestic conditions. For example, a policy maker may be tempted to overstate the social cost of raising tax revenue from domestic workers whenever this results in a reduction in the tax levied on domestic workers. The reason is that the associated inflation tax will be partially borne by foreign investors resulting in a redistribution from foreign investors to domestic workers.

The most simple fiscal rules require member countries to raise sufficient tax revenue to meet public expenditure, irrespective on the social cost of taxing domestic workers. However, countries will in general ex ante agree to use the inflation tax in at least some states of the world, despite the problems introduced by asymmetric information. A fiscal rule that is optimal when fiscal rules are constrained to depend only on domestic conditions prescribes a minimum amount of tax revenue to be collected from workers in each country. ${ }^{4}$ Alternatively, such rules can be seen as prescribing an upper bound on domestic budget deficits, similar to the one stipulated by the Maastricht Treaty and Stability and Growth Pact of the European Union.

This paper studies fiscal rules that can depend on domestic as well as foreign conditions. This creates an intratemporal margin for incentive provision. I denote the use of such intratemporal reciprocity as "coordination". In that sense, the model delivers a rationale for fiscal policy coordination within a monetary union that is derived from agency frictions alone. The central result of the paper is to show how the nature of coordination

\footnotetext{
${ }^{4}$ See Melumad and Shibano (1991) and Amador and Bagwell (2011) for a discussion of when such a mechanism is optimal.
} 
evolves over time when fiscal rules can exhibit history dependence. Then intertemporal reciprocity is used, in addition to intratemporal reciprocity, to incentivize policy makers to reveal the domestic conditions they are facing. ${ }^{5}$ Optimal fiscal rules are derived by solving a mechanism design problem under full commitment. ${ }^{6}$

First, I show that a history of symmetric domestic conditions across the monetary union leads to policy coordination that takes the form of positively correlated efforts to raise tax revenue from domestic workers across member countries (with shocks to domestic conditions across countries being i.i.d.). As long as countries continue to receive the same shocks fiscal policy is First Best efficient. When countries experience different shocks to the social cost of domestic taxation then the country with low cost of domestic taxation may raise more tax revenue than needed to balance its domestic budget to prevent inflation from rising too much.

Second, I show that a history of asymmetric domestic conditions leads to coordination that takes the form of retaliatory fiscal policies. We say that a country is allowed to retaliate if it is allowed to collect inefficiently low tax revenue as an immediate (i.e. within-period) response to a report of high social cost of taxation abroad. To gain intuition consider the following argument: It is shown that to reward a particular country for relatively higher domestic taxation in the past it will be allowed to decrease its domestic taxation more in states where its domestic social cost of taxation is high. However, by making one country's fiscal policy more responsive to reported domestic conditions, the incentive to overstate the social cost of taxation increases in both countries. To restore incentive-compatibility optimal

\footnotetext{
${ }^{5}$ Here, intertemporal reciprocity refers to the standard notion of assigning 'continuation values' that summarize the history of reports such that prescribed actions in the following period are functions of these values. See Thomas and Worrall (1990) for a model of insurance over time under information asymmetry. This paper differs from studies of optimal coinsurance under asymmetric information in that I consider an aggregate budget can be expanded at a (non-monetary) cost that must be shared equally.

${ }^{6}$ For the case of the European Monetary Union it is often believed that its resolution would have severe adverse economic and political consequences. In this paper I do not model incentives to participate ex ante or at any interim stage.
} 
fiscal rules allow for retaliation.

The paper is organized as follows. The remainder of this section provides a brief literature review, section 2 introduces the model, section 3 derives optimal fiscal rules and section 4 concludes. All proofs can be found in the appendix.

\subsection{Related literature}

When sovereign nations share ties via trade and finance, inefficient allocations are likely to arise due to external effects. Important examples are protectionist trade and monetary policies, insufficient financial market regulation, or sovereign defaults. A number of countries may hence find it beneficial to agree on a set of rules in an attempt to limit inefficient actions by participating countries. Alesina, Angeloni, and Etro (2005) formulate a class of problems faced by such "international unions" and study the welfare implications of several institutional arrangements. An important problem in practice, and addressed in the literature, arises when individual countries privately observe domestic conditions and side payments are not possible (which is certainly plausible when domestic conditions affect the solvency of the country). Amador and Bagwell (2011) characterize optimal mechanisms when rules prescribing domestic actions are restricted to depend on domestic conditions only. ${ }^{7}$ In this paper, I study the case where rules may depend on both domestic and foreign conditions and where such policy coordination leads to an increase in ex-ante joint welfare. I characterize the optimal dynamic mechanism precisely for a very simple functional form.

The paper connects to the theoretical literature on optimal delegation (Melumad and Shibano (1991) and Amador and Bagwell (2011)) and on intertemporal reciprocity (Athey and Bagwell (2001), Abdulkadiroglu and Bagwell (2005), Hauser and Hopenhayn (2008)), under imperfect monitoring. By focusing on a symmetric two-agent environment where the

\footnotetext{
${ }^{7}$ See Melumad and Shibano (1991) for a special case where a simple cut-off rule is optimal. Athey, Atkeson, and Kehoe (2005) and Amador, Werning, and Angeletos (2006) consider a similar case and show that the constant cut-off remains optimal when the economy is repeated over time.
} 
need for monitoring results from externalities and where actions are simultaneous the model provides an example for optimality of immediate reciprocity. Roberts (1985) shows that in an environment where firms are in static Cournot competition collusion in the presence of private costs optimally involves positively correlated quantities (full commitment case). ${ }^{8}$ A similar incentive problem arises when two pastry chefs share a produced pie in a fixed proportion and privately observe their disutility from working on the pie. When one of the chefs claims currently high discomfort from baking the other chef should reduce effort as well. See Alchian and Demsetz (1972) for a discussion of situations with ad-hoc profit sharing.

The paper also connects to an extensive literature on the design of fiscal policy in a monetary union. There is series of contributions studying the case where the central bank can fully observe economic and political conditions in member countries, see Beetsma and Uhlig (1999), Dixit and Lambertini (2003), Cooper and Kempf (2004) and Chari and Kehoe (2007). The problem pointed out by these papers arises when the central bank cannot commit not to monetize inefficiently high budget deficits. ${ }^{9}$ In this paper, I study the case where there is full commitment and where countries have an informational advantage regarding domestic economic and political conditions. Doepke and Schneider (2006) study redistributional effects of episodes of unanticipated inflation while Phelps (1973) shows that an inflation tax can be a useful tool in public finance. Click (1998) studies the use of seignorage for a crosssection of countries, and Persson, Persson, and Svensson (1987) show that a way to restore time-consistency consists in the government holding nominal claims. Rodden (2006) examines the common pool problem for a number of federations and reports that a higher degree of risk-sharing (identified as federal states having similar financing costs, as for example in

\footnotetext{
${ }^{8}$ See Goltsman and Pavlov (2011) for an extension of his setup to limited commitment.

${ }^{9}$ The problem is treated in a more general fashion in the common-pool literature, see Velasco (2000) and Krogstrup and Wyplosz (2010), where actions by municipalities, federal states, or countries lead to externalities and may hence be inefficient.
} 
Brazil and Germany) coincides with stricter fiscal rules imposed on federal states.

\section{Model}

Time, agents, endowments, uncertainty, and information:

There are two time periods $t=1,2$. There is a consumption good. There are two ex-ante symmetric countries, and one monetary authority. In each country, there is a government, a measure one of identical workers and a measure one of identical investors. In every period, with certainty, workers each receive an endowment $w>0$, investors each receive an endowment $r>0$, and governments each face exogenously given expenditures $g \in[0, r]$. In each period, country $j=1,2$ experiences a preference shock $s_{j, t} \in S=\left\{s_{L}, s_{H}\right\}$ with equal probability. Note that preference shocks are independent across countries and over time. It is assumed that only the government in country $j$ can observe $s_{j, t}$. Let $s^{t}$ denote the history of realizations of preference shocks across the monetary union at time $t=1,2$ such that $s^{t} \in S^{2 t}$. The function $\theta: S \rightarrow \Theta=\left\{\theta_{L}, \theta_{H}\right\}$ maps the preference shock into a preference parameter $\theta\left(s_{k}\right)=\theta_{k}, k=L, H$. It is assumed that $E\left(\theta\left(s_{j, t}\right)\right)=\mu<1$ and that $\frac{1}{2}<\theta_{L}<\mu<1<\theta_{H}$.

Preferences and aggregate resources:

For country $j=1,2$, let $c_{j}^{W}=\left\{c_{j, t}^{W}\left(s^{t}\right)\right\}_{t=1,2}$ and $c_{j}^{I}=\left\{c_{j, t}^{I}\left(s^{t}\right)\right\}_{t=1,2}$ be consumption paths for workers and investors respectively. The government in country $j$ ranks consumption paths $\left\{c_{j}^{W}, c_{j}^{I}\right\}$ according to a welfare criterion $W\left(\left\{c_{j}^{W}, c_{j}^{I}\right\}\right)$, where

$$
W\left(\left\{c_{j}^{W}, c_{j}^{I}\right\}\right)=E\left(\theta\left(s_{j, 1}\right) c_{j, 1}^{W}\left(s^{1}\right)+c_{j, 1}^{I}\left(s^{1}\right)+\delta\left(\theta\left(s_{j, 2}\right) c_{j, 2}^{W}\left(s^{2}\right)+c_{j, 2}^{I}\left(s^{2}\right)\right)\right),
$$


if $\left\{c_{j}^{W}, c_{j}^{I}\right\}$ non-negative and $W\left(\left\{c_{j}^{W}, c_{j}^{I}\right\}\right)=-\infty$ else. The parameter $\delta \in(0,1]$ is a discount factor. The preference parameters are welfare weights and can be thought of as representing political pressure from workers or the dead-weight cost of taxing workers. The monetary authority ranks consumption paths $\left\{c_{j}^{W}, c_{j}^{I}\right\}_{j=1,2}$ according to

$$
\Omega\left(\left\{c_{j}^{W}, c_{j}^{I}\right\}_{j=1,2}\right)=W\left(\left\{c_{1}^{W}, c_{1}^{I}\right\}\right)+W\left(\left\{c_{2}^{W}, c_{2}^{I}\right\}\right)
$$

The monetary union's aggregate resource constraint is given by

$$
2 g+\sum_{j=1,2}\left[c_{j}^{W}\left(s^{t}\right)+c_{j}^{I}\left(s^{t}\right)\right] \leq 2(w+r), \quad \text { for each } s^{t} \in S^{2 t}, t=1,2
$$

Definition 1. Fiscal policies feature coordination if $c_{j}^{W}\left(s^{t}\right)$ depends on $s_{-j, t}$ for at least one $j=1,2$ or $t=1,2$.

\section{Taxation:}

In each period $t=1,2$, the government in country $j=1,2$ can impose a lump sum tax on domestic workers, $\tau_{j, t}^{W} \in[0, w] .{ }^{10}$ The monetary authority can impose a lump sum tax on investors in country $j=1,2, \tau_{j, t}^{\pi} \in[g-w, r]$. For example, we could think of $\tau_{j, t}^{\pi}$ as an inflation tax, where it is implied that only investors hold nominal assets. ${ }^{11}$ The inflation tax is restricted to be equal across investors throughout the entire monetary union, $\tau_{1, t}^{\pi}=\tau_{2, t}^{\pi}=\tau_{t}^{\pi}$. This assumption is meant to capture that investor income is mobile across the monetary union, but worker income is not. It is also assumed that, in each period, the inflation tax is chosen before domestic taxes are chosen (see figure 1).

\footnotetext{
${ }^{10}$ Bounding taxation of workers from below at zero can be justified by assuming a marginal dead-weight cost of subsidizing strictly greater than $\theta_{H}-1$. This greatly facilitates the exposition: the non-negativity constraint on investor consumption never binds which allows for studying fiscal policy coordination as arising from information asymmetries alone.

${ }^{11}$ To keep the analysis tractable the model does not distinguish between actual and expected inflation taxation. However, Reinhart and Sbrancia (2011) argue that a large and permanent increase in the ratio of public debt to GDP often leads to some form of "financial repression".
} 


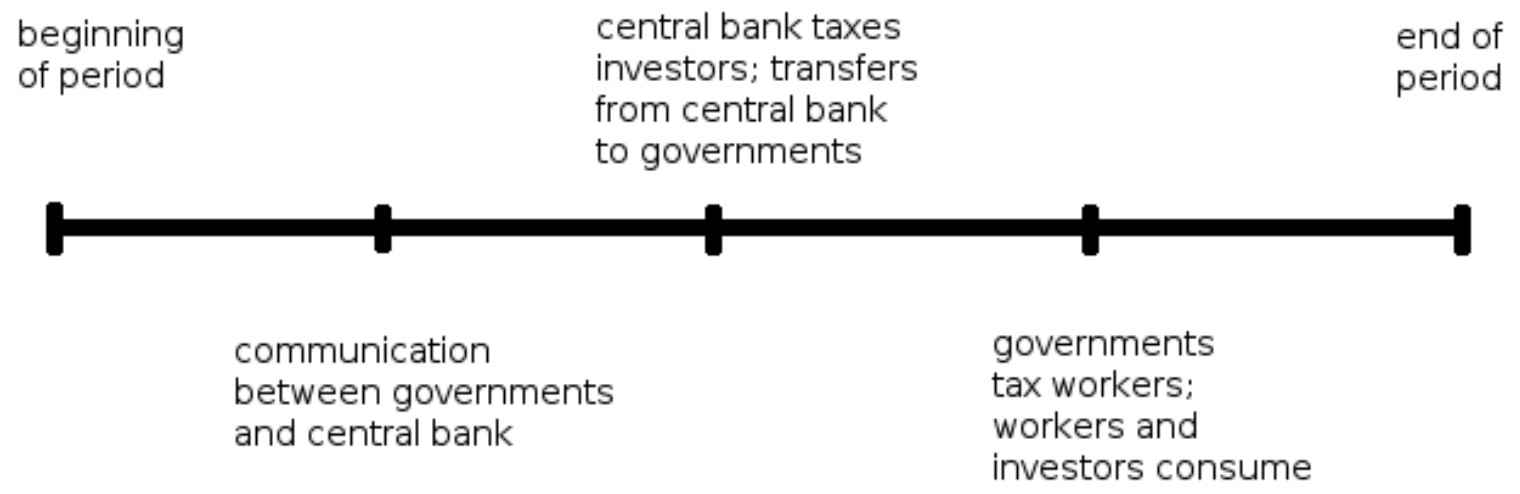

Figure 1: Before taxing domestic workers each government has the opportunity to communicate with the central bank. Since governments must choose taxes on domestic workers to satisfy their budget constraints - i.e. (4) must hold - the transfers that the central bank implements after communicating with governments pin down consumption of workers and investors in both countries. 
A government has two sources of income: domestic tax revenue $\tau_{j, t}^{W}$ and a transfer from the monetary authority $T_{j, t}, j=1,2$. Given the transfer, it must choose taxation of domestic workers such that domestic expenditures are financed

$$
\tau_{j, t}^{W}+T_{j, t} \geq g, \quad j=1,2, t=1,2
$$

The monetary authority finances transfers to member countries by levying an inflation tax on investors such that its budget constraint becomes

$$
2 \tau_{t}^{\pi} \geq T_{1, t}+T_{2, t}, \quad t=1,2
$$

\section{Consumption:}

Given taxes chosen by individual governments and the monetary authority, workers and investors consume their after tax income given by

$$
c_{j, t}^{W}=w-\tau_{j, t}^{W}, \quad c_{j, t}^{I}=r-\tau_{t}^{\pi}, \quad j=1,2, t=1,2 .
$$

\section{Optimization problem:}

Each government prefers to have the highest possible level of domestic welfare as measured by the function $W$. The monetary authority prefers to have the highest possible level of monetary union wide welfare as measured by the function $\Omega$. Note that once the monetary authority chooses transfers, domestic taxation is pinned down by (4) as governments derive no benefit from leaving (4) slack. Also note that (6) determines consumption of workers and investors for given taxation. It makes then sense to focus on the monetary authority's optimization problem: the maximization of (2) subject to (4), (5), (6), and governments' private information about preference shocks. 


\subsection{First-Best fiscal policies}

A First Best is defined as the solution to the monetary authority's optimization problem in the absence of informational asymmetry,

$$
\max _{\left\{c_{j}^{W}, c_{j}^{I}\right\}_{j=1,2}} \Omega\left(\left\{c_{j}^{W}, c_{j}^{I}\right\}_{j=1,2}\right), \text { subject to (4), (5), and (6). }
$$

When no resources are wasted, then the budget constraints of workers, investors, governments and monetary authority can be combined to obtain an expression for investor consumption as a function of the monetary union's resources and worker consumption.

$$
c_{j, t}^{I}\left(s^{t}\right)=r+w-g-\frac{1}{2}\left[c_{1, t}^{W}\left(s^{t}\right)+c_{2, t}^{W}\left(s^{t}\right)\right], \quad t=1,2, j=1,2,
$$

where $c_{j, t}^{W} \in[0, w]$. A First-Best allocation can then be found as the solution to the following problem.

$$
\max _{\left\{c_{j}^{W}\right\}_{j=1,2}} \tilde{\Omega}\left(\left\{c_{j}^{W}\right\}_{j=1,2}\right)=\sum_{t=1,2} \delta^{t-1} \sum_{j=1,2} \frac{1}{4} \sum_{s^{t} \in S^{t}}\left[\theta\left(s_{j, t}\right)-1\right] c_{j, t}^{W}\left(s^{t}\right) .
$$

Lemma 1. The First-Best allocation is fully characterized by worker consumption given by

$$
c_{j, t}^{W}\left(s^{t}\right)=\left\{\begin{array}{ll}
0, & \text { if } \theta\left(s_{j, t}\right)=\theta_{L} ; \\
w, & \text { if } \theta\left(s_{j, t}\right)=\theta_{H},
\end{array} \quad t=1,2, j=1,2 .\right.
$$

Note that the First-Best allocation is time-independent (there is no state variable). Also note that worker consumption (and thus fiscal policy) in country $j$ only depends on the preference shock in country $j$. That is, in the absence of informational asymmetry there is no need for fiscal policy coordination. ${ }^{12}$

\footnotetext{
${ }^{12}$ Fiscal policy can be coordinated in the First-Best if investors' consumption non-negativity constraints bind in certain states of the world, see footnote 10.
} 


\subsection{Role of incentives}

When the monetary authority relies on governments to communicate respective preference shocks, then the First-Best level of welfare is not attainable. To see this, note that a government observing a low domestic preference shock $\theta_{L}$ knows that by communicating $\theta_{H}$ instead to the monetary authority, domestic workers will enjoy an increase in utility of $\theta_{L} w$ while domestic investors will suffer a decrease in utility of $\frac{1}{2} w$. On net, domestic welfare

will increase by $\Delta W=\left(\theta_{L}-\frac{1}{2}\right) w>0$ as the result of such misreporting of the domestic preference shock.

\subsection{Simple fiscal rules}

If the monetary authority would use the function $c_{j, t}^{W}$ described in lemma 1 to map reported (rather than actual, as presumed in the lemma) preference shocks into worker consumption levels (i.e. transfers to governments) then its objective value would take the value $\tilde{\Omega}=2(1+$ $\delta)(\mu-1) w<0$, since governments would always pretend to value worker consumption more relative to that of investors. Clearly, it could do better, $\tilde{\Omega}=0$, by simply setting $c_{j, t}^{W}=0$ irrespective of reported preference shocks. This corresponds to a subsidy for investors of $w-g$ in each country. Call this the simple fiscal rule.

When the preference shock can take many different values (not just two) the simple rule generalizes to an upper bound on transfers to governments (equivalently, an upper bound on domestic pre-transfer budget deficits). See Melumad and Shibano (1991) and Amador and Bagwell (2011) for a discussion of such rules. 


\section{An optimal mechanism}

In this section, I make use of the revelation principle and focus on characterizing a direct mechanism. The monetary authority will choose a mapping from truthful government reports of respective domestic preference shocks into respective domestic fiscal policies. To be precise, the monetary authority sets transfers to governments based on their reports, and governments tax domestic workers to close the remaining budget deficit. Both governments report their respective domestic preference shock to the monetary authority at the same time.

A familiar feature of an optimal mechanism will be that a country's period welfare may vary over time, depending on the realization of preference shocks in the past (see Thomas and Worrall, 1990). A new feature will be policy coordination: current transfers to a particular country will depend on current preference shocks experienced by both countries in the monetary union. This immediate reciprocity will be shown to depend on history in an interesting way and will manifest itself as explicit retaliation in certain states of the world.

\subsection{Second period}

Given that the model only has two periods, a recursive approach can be readily laid out. In period $t=2$, let $v \in\left[\underline{v}_{1}, \bar{v}_{1}\right]$ be the second period welfare the monetary authority promises to government two $\left(\underline{v}_{1}\right.$ and $\bar{v}_{1}$ will be derived below). Given $v$, let $c_{j}\left(s_{1}, s_{2}\right)$ be consumption of workers in country $j=1,2$ that the monetary authority allows when government one reports domestic preference shock $s_{1}$ and government reports domestic preference shock $s_{2}$. Formally, $c_{j}: S^{2} \rightarrow[0, w]$.

Since the monetary authority is bound by its promise, the fiscal rules $\left\{c_{j}\right\}_{j=1,2}$ must satisfy the following promise keeping constraint. 


$$
\frac{1}{4} \sum_{s_{1} \in S} \sum_{s_{2} \in S}\left[\theta\left(s_{2}\right) c_{2}\left(s_{1}, s_{2}\right)-\frac{1}{2} c_{1}\left(s_{1}, s_{2}\right)-\frac{1}{2} c_{2}\left(s_{1}, s_{2}\right)\right] \geq v
$$

Governments will report the domestic preference shock truthfully whenever the following incentive compatibility constraints hold.

$$
\begin{aligned}
\frac{1}{2} \sum_{s_{2} \in S}\left[\theta\left(s_{L}\right) c_{1}\left(s_{L}, s_{2}\right)\right. & \left.-\frac{1}{2} c_{1}\left(s_{L}, s_{2}\right)-\frac{1}{2} c_{2}\left(s_{L}, s_{2}\right)\right] \\
& \geq \frac{1}{2} \sum_{s_{2} \in S}\left[\theta\left(s_{L}\right) c_{1}\left(s_{H}, s_{2}\right)-\frac{1}{2} c_{1}\left(s_{H}, s_{2}\right)-\frac{1}{2} c_{2}\left(s_{H}, s_{2}\right)\right], \\
\frac{1}{2} \sum_{s_{1} \in S}\left[\theta\left(s_{L}\right) c_{2}\left(s_{1}, s_{L}\right)\right. & \left.-\frac{1}{2} c_{1}\left(s_{1}, s_{L}\right)-\frac{1}{2} c_{2}\left(s_{1}, s_{L}\right)\right] \\
& \geq \frac{1}{2} \sum_{s_{1} \in S}\left[\theta\left(s_{L}\right) c_{2}\left(s_{1}, s_{H}\right)-\frac{1}{2} c_{1}\left(s_{1}, s_{H}\right)-\frac{1}{2} c_{2}\left(s_{1}, s_{H}\right)\right] .
\end{aligned}
$$

When conditions (11) and (12) are satisfied, governments will have no incentive to understate the welfare weight of domestic workers as long as the following monotonicity condition holds

$$
\sum_{s_{2} \in S}\left[c_{1}\left(s_{H}, s_{2}\right)-c_{1}\left(s_{L}, s_{2}\right)\right] \geq 0, \text { and } \sum_{s_{1} \in S}\left[c_{2}\left(s_{1}, s_{H}\right)-c_{2}\left(s_{1}, s_{L}\right)\right] \geq 0
$$

Condition (13) differs from the usual monotonicity condition in that the function is required to increase in the own type only in expectation. However, it will not bind and can be ignored.

Let $P(v)$ be the highest period two welfare the monetary authority can deliver to government one given the promise $v$ to government two. That is, $P(v)$ is defined as

$$
P(v)=\max _{\left\{c_{j}\right\}_{j=1,2}} \frac{1}{4} \sum_{s_{1} \in S} \sum_{s_{2} \in S}\left[\theta\left(s_{1}\right) c_{1}\left(s_{1}, s_{2}\right)-\frac{1}{2} c_{1}\left(s_{1}, s_{2}\right)-\frac{1}{2} c_{2}\left(s_{1}, s_{2}\right)\right]
$$


subject to (10), (11), and (12). Then the graph of $P,\left\{\left(v_{1}, v_{2}\right): v_{2} \in\left[\underline{v}_{1}, \bar{v}_{1}\right], v_{1}=P\left(v_{2}\right)\right\}$, is just the set of incentive compatible Pareto-optimal allocations in period two. Of particular interest is the value $v_{0}$ for which $P\left(v_{0}\right)=v_{0}$ (recall that countries are symmetric ex ante).

Theorem 1 shows that the monetary authority can strictly improve upon the simple rule (see section 2.3) by making transfers to each government depend on reports about the domestic preference shock by both governments. For example, the monetary authority could use the fiscal policies characterized in the theorem in either period.

Theorem 1. Suppose $v=v_{0}$, then the incentive compatible Pareto optimal allocation is given by

$$
\begin{aligned}
& c_{1}\left(s_{H}, s_{H}\right)=c_{2}\left(s_{H}, s_{H}\right)=w, \\
& c_{1}\left(s_{H}, s_{L}\right)=c_{2}\left(s_{L}, s_{H}\right)=\frac{1-\theta_{L}}{\theta_{L}} w, \\
& c_{1}\left(s_{L}, \cdot\right)=c_{2}\left(\cdot, s_{L}\right)=0 .
\end{aligned}
$$

Welfare enjoyed by each government is given by $v_{0}=\frac{2 \mu-\theta_{L}-1}{4 \theta_{L}} w>0$.

The theorem shows that, optimally, a government is allowed to react more strongly to a domestic high preference shock (by lowering taxation of workers more) if the other government reports a high preference shock as well. The monetary authority grants governments flexibility with respect to domestic shocks when setting domestic fiscal policy, but requires that such flexibility be positively correlated across members of the monetary union. While consumption of domestic workers is inefficiently low when the domestic preference shock exceeds the foreign one, it is exactly this distortion that allows for efficient domestic worker consumption when the domestic preference shock is low. Note that $c_{1}\left(s_{L}, s_{H}\right)=c_{2}\left(s_{H}, s_{L}\right)=0$ means that if $w>g$ then the country with lower social cost of domestic taxation will have a pre-transfer budget surplus. That means the country makes a payment to the monetary authority to prevent investor income from decreasing too much 
throughout the monetary union.

Definition 2. Let the variance of preference shock be

$$
\sigma^{2}=\frac{1}{2}\left(\mu-\theta_{L}\right)^{2}+\frac{1}{2}\left(\mu-\theta_{H}\right)^{2}=\left(\mu-\theta_{L}\right)^{2}
$$

Then preference shocks have high mean and dispersion if

$$
\mu>\frac{1}{2}+\frac{1}{\sqrt{8}} \text {, and } \sigma>\sqrt{\mu(1-\mu)} .
$$

Definition 3. Government one is allowed to retaliate if $c_{1}\left(s_{L}, s_{H}\right)>0$. Government two is allowed to retaliate if $c_{2}\left(s_{H}, s_{L}\right)>0$.

The definition of retaliation used in this paper differs from the notion of a "price war" (e.g. Athey, Bagwell, and Sanchirico, 2004) in that it describes a kind of immediate, rather than intertemporal, reciprocity. That is, retaliation is with respect to current, not past actions and closer to the notion of reciprocal monitoring under equal profit sharing mentioned in Alchian and Demsetz (1972). ${ }^{13}$

When $v<v_{0}$ the question arises how we can make country one better off. One possibility, starting from the allocation characterized by theorem 1, is to increase $c_{1}\left(s_{H}, s_{L}\right)$ and to decrease $c_{2}\left(s_{L}, s_{H}\right)$. However, when the dispersion of preference shocks is high then the monetary authority is not willing to reduce worker consumption in country two in the state $\left(s_{L}, s_{H}\right) .{ }^{14}$ In order to offset the pressure that an increase in $c_{1}\left(s_{H}, s_{L}\right)$ puts on both incentive compatibility constraints, the monetary authority introduces a notion of retaliation. The following theorem 2 characterizes the optimal allocation for $v<v_{0}$ (where the case $v>v_{0}$

\footnotetext{
${ }^{13}$ Note that, just like the price war, while retaliation is socially inefficient it is privately efficient (each government prefers taxes on domestic workers as low as possible in every state).

${ }^{14}$ One could say the monetary authority prefers to avoid "inefficient austerity" when countries experience different preference shocks.
} 
follows from symmetry). ${ }^{15}$

Theorem 2. Suppose preference shocks have high mean and dispersion, then for $v \in\left[\underline{v}_{1}, v_{0}\right]$ the optimal allocation is given by

$$
\begin{aligned}
& c_{1}\left(s_{H}, s_{H}\right)=c_{2}\left(s_{H}, s_{H}\right)=w, \\
& c_{2}\left(s_{L}, s_{H}\right)=\frac{1-\theta_{L}}{\theta_{L}} w, \\
& c_{1}\left(s_{H}, s_{L}\right)=\frac{1-\theta_{L}}{\theta_{L}} w+4\left(v_{0}-v\right), \\
& c_{2}\left(\cdot, s_{L}\right)=0, \\
& c_{1}\left(s_{L}, s_{L}\right)=0, \quad c_{1}\left(s_{L}, s_{H}\right)=4\left(v_{0}-v\right),
\end{aligned}
$$

where $\underline{v}_{1}=\frac{2 \mu-3 \theta_{L}}{4 \theta_{L}} w$. Government one enjoys welfare of $P(v)=2 \mu v_{0}-(2 \mu-1) v$.

The theorem shows that, as $v$ decreases, the monetary authority delivers higher welfare $P(v)$ to government one by allowing its fiscal policy to accommodate high domestic preference shocks to a greater extent, i.e. $c_{1}\left(s_{H}, s_{L}\right)$ increases $\left(c_{1}\left(s_{H}, s_{H}\right)=w\right.$ is already at a corner). However, this weakens incentives of both governments to report preference shocks truthfully. The monetary authority restores incentive-compatibility by allowing government one to retaliate. On the one hand, fear of retaliation reduces the incentive of government two to wrongfully claim high social cost of taxing domestic workers. On the other hand, the possibility of retaliation is a way of directly rewarding government one for revealing low social cost of taxing domestic workers.

\footnotetext{
${ }^{15}$ The restriction $v \geq \underline{v}_{1}$ is arbitrary. In the appendix I extend theorem 2 to allow for all technologically feasible values for $v$. This is rather tedious and does not add any new insights.
} 


\subsection{First period}

In period one, the monetary authority can assign continuation values $v_{1}, v_{2}$ to governments to strengthen their incentives to report respective domestic preference shock truthfully,

$$
v_{j}: S^{2} \rightarrow[\underline{v}, \bar{v}], \quad v_{j}:\left(s_{1}, s_{2}\right) \mapsto v_{j}\left(s_{1}, s_{2}\right),
$$

where again $s_{1}, s_{2}$ denote reported shocks. The monetary authority's mechanism design problem is as follows:

$$
\max _{\left\{c_{j}, v_{j}\right\}_{j=1,2}} \frac{1}{4} \sum_{s_{1} \in S} \sum_{s_{2} \in S}\left[\left(\theta\left(s_{1}\right)-1\right) c_{1}\left(s_{1}, s_{2}\right)+\left(\theta\left(s_{2}\right)-1\right) c_{2}\left(s_{1}, s_{2}\right)+\delta\left(v_{1}\left(s_{1}, s_{2}\right)+v_{2}\left(s_{1}, s_{2}\right)\right)\right]
$$

subject to incentive compatibility

$$
\begin{aligned}
\frac{1}{2} \sum_{s_{2} \in S}\left[\theta\left(s_{L}\right) c_{1}\left(s_{L}, s_{2}\right)\right. & \left.-\frac{1}{2} c_{1}\left(s_{L}, s_{2}\right)-\frac{1}{2} c_{2}\left(s_{L}, s_{2}\right)+\delta v_{1}\left(s_{L}, s_{2}\right)\right] \\
& \geq \frac{1}{2} \sum_{s_{2} \in S}\left[\theta\left(s_{L}\right) c_{1}\left(s_{H}, s_{2}\right)-\frac{1}{2} c_{1}\left(s_{H}, s_{2}\right)-\frac{1}{2} c_{2}\left(s_{H}, s_{2}\right)+\delta v_{1}\left(s_{H}, s_{2}\right)\right] \\
\frac{1}{2} \sum_{s_{1} \in S}\left[\theta\left(s_{L}\right) c_{2}\left(s_{1}, s_{L}\right)\right. & \left.-\frac{1}{2} c_{1}\left(s_{1}, s_{L}\right)-\frac{1}{2} c_{2}\left(s_{1}, s_{L}\right)+\delta v_{2}\left(s_{1}, s_{L}\right)\right] \\
& \geq \frac{1}{2} \sum_{s_{1} \in S}\left[\theta\left(s_{L}\right) c_{2}\left(s_{1}, s_{H}\right)-\frac{1}{2} c_{1}\left(s_{1}, s_{H}\right)-\frac{1}{2} c_{2}\left(s_{1}, s_{H}\right)+\delta v_{2}\left(s_{1}, s_{H}\right)\right]
\end{aligned}
$$

and feasibility

$$
c_{j}\left(s_{1}, s_{2}\right) \in[0, w], \text { and } \underline{v}_{1} \leq v_{1}\left(s_{1}, s_{2}\right) \leq P\left(v_{2}\left(s_{1}, s_{2}\right)\right) \text { for all }\left(s_{1}, s_{2}\right) \in S^{2},
$$


where $c_{j}$ now denotes worker consumption in the first period (everything that happens in the second period is captured by $v_{j}$ ). Theorem 3 follows as the analog to theorem 1 with the difference that the monetary authority now uses continuation values to make fiscal policies more responsive to domestic shocks.

Theorem 3. Suppose preference shocks have high mean and dispersion. Then the optimal mechanism is characterized by first period worker consumption

$$
\begin{aligned}
& c_{1}\left(s_{H}, s_{H}\right)=c_{2}\left(s_{H}, s_{H}\right)=w, \\
& c_{1}\left(s_{H}, s_{L}\right)=c_{2}\left(s_{L}, s_{H}\right)=\frac{1-\theta_{L}}{\theta_{L}} w+\frac{\delta}{\theta_{L}}\left(P\left(\underline{v}_{1}\right)-\underline{v}_{1}\right), \\
& c_{1}\left(s_{L}, \cdot\right)=c_{2}\left(\cdot, s_{L}\right)=0,
\end{aligned}
$$

and second period values

$$
\begin{aligned}
& v_{1}\left(s_{L}, s_{L}\right)=v_{2}\left(s_{L}, s_{L}\right)=v_{0}, \\
& v_{1}\left(s_{H}, s_{L}\right)=v_{2}\left(s_{L}, s_{H}\right)=\underline{v}_{1}, \\
& v_{1}\left(s_{L}, s_{H}\right)=v_{2}\left(s_{H}, s_{L}\right)=P\left(\underline{v}_{1}\right), \\
& v_{1}\left(s_{H}, s_{H}\right)=v_{2}\left(s_{H}, s_{H}\right)=v_{0} .
\end{aligned}
$$

The theorem shows, unsurprisingly, that worker consumption can respond more to domestic preference shocks when the monetary authority makes period two fiscal policies contingent on reported period one preference shocks. In combination with theorem 2 this yields the main result of the paper. Theorem 4 states that a history of asymmetric shocks across members of the monetary union gives rise to retaliatory fiscal policies. ${ }^{16}$

Theorem 4. Suppose preference shocks have high dispersion. Let $s_{1}, s_{2} \in S$ be preference shocks in

\footnotetext{
${ }^{16}$ There is no retaliation in the first period at all. In numerical exercises with strictly concave worker utility functions the increase in retaliation can be less abrupt.
} 
period one. If $\theta\left(s_{1}\right)<\theta\left(s_{2}\right)$ then government one is allowed to retaliate in the second period. If $\theta\left(s_{1}\right)>\theta\left(s_{2}\right)$ then government two is allowed to retaliate in the second period.

The theorem has an immediate policy implication. If members of a monetary union experience current disagreement (different preference shocks) about the common monetary policy then future fiscal policy should become more tightly coordinated in the future. The welfare loss due to tighter future coordination (within-period retaliation) is small relative to the benefits derived from a common monetary policy that is better able to respond to shocks that only affect individual (but not all) member countries. ${ }^{17}$

\subsection{Dynamics of the inflation tax}

The analysis in this paper implies that a monetary union can experience shifts in monetary policy over time as a result of past disagreement. ${ }^{18}$ These shifts take the form of changes in the expected inflation tax. To see this note that the inflation tax is positively related to worker consumption. Then the expected inflation tax in period one is equal to (up to a constant)

$$
E\left(c_{1,1}^{W}+c_{2,1}^{W}\right)=\frac{w}{4 \theta_{L}}+\frac{\delta}{4 \theta_{L}}\left(P\left(\underline{v}_{1}\right)-\underline{v}_{1}\right)=\frac{w}{4 \theta_{L}}+\frac{\delta \mu}{2 \theta_{L}}\left(v_{0}-\underline{v}_{1}\right),
$$

where I used theorems 2 and 3. The conditional expected inflation tax in period two is equal to (up to the same constant)

$$
E\left(c_{1,2}^{W}+c_{2,2}^{W} \mid v_{1}, v_{2}\right)= \begin{cases}\frac{w}{4 \theta_{L}} & \text { if } v_{1}=v_{2}=v_{0} \\ \frac{w}{4 \theta_{L}}+v_{0}-\underline{v}_{1} & \text { else. }\end{cases}
$$

\footnotetext{
${ }^{17}$ Again, it is important to note that retaliation in the sense used in this paper is different from "price wars" in for example Athey et al. (2004).

${ }^{18}$ For example, Sims and Zha (2006) argue that there may be benefits to modeling significant changes in monetary policy as resulting from large external shocks for time-invariant monetary policy rules.
} 
where I again used theorems 2 and 3 . Then disagreement in period one, $v_{1} \neq v_{2}$, leads to an increase in the expected inflation tax since $\frac{\delta \mu}{2 \theta_{L}}<1$ for $\delta \leq 1$.

\section{Conclusion}

This paper studies the design of optimal fiscal rules for members of a monetary union when there is asymmetric information about individual countries' domestic economic conditions. Since the information asymmetry concerns countries' ability to raise tax revenue domestically, a mechanism that makes use of side payments is not available. As a result, fiscal policy coordination becomes a characteristic of optimal fiscal rules. For example, fiscal rules that feature coordination lead to higher ex-ante welfare than simple upper bounds on domestic budget deficits. The paper studies how fiscal policy coordination evolves over time and implications for the common monetary policy. First, it is shown that a symmetric history of taxation efforts across the monetary union leads to fiscal policy coordination in the form of positively correlated efforts to raise tax revenue domestically. Second, it is shown that the union's monetary policy can better accommodate a single country's current difficulty in raising tax revenue domestically by tightening fiscal policy coordination in the future. Tightened fiscal policy coordination takes the form of allowing for the incidence of within-period retaliation against that country. In that sense, retaliation is not a direct punishment for past behavior but rather a means to facilitate it. The result of a tightening of policy coordination, following a past disagreement, is an increase in the expected inflation tax throughout the monetary union. 


\section{References}

Abdulkadiroglu, A. and K. Bagwell (2005). Trust, reciprocity and favors in cooperative relationships. In Proceedings of University of Maryland, Department of Economics, Workshop in Industrial Organization and Microeconomic Theory.

Alchian, A. and H. Demsetz (1972). Production, information costs, and economic organization. The American Economic Review 62(5), 777-795.

Alesina, A., I. Angeloni, and F. Etro (2005). International unions. American Economic Review 95(3), 602-615.

Amador, M. and K. Bagwell (2011). The theory of optimal delegation with an application to tariff caps. Technical report, Working paper.

Amador, M., I. Werning, and G. Angeletos (2006). Commitment vs. flexibility. Econometrica $74(2), 365-396$.

Athey, S., A. Atkeson, and P. Kehoe (2005). The optimal degree of discretion in monetary policy. Econometrica 73(5), 1431-1475.

Athey, S. and K. Bagwell (2001). Optimal collusion with private information. RAND Journal of Economics 32(3), 428-465.

Athey, S., K. Bagwell, and C. Sanchirico (2004). Collusion and price rigidity. Review of Economic Studies 71(2), 317-349.

Beetsma, R. and H. Uhlig (1999). An analysis of the stability and growth pact. The Economic Journal 109(458), 546-571.

Chari, V. and P. Kehoe (2007). On the need for fiscal constraints in a monetary union. Journal of Monetary Economics 54(8), 2399-2408. 
Click, R. (1998). Seigniorage in a cross-section of countries. Journal of Money, Credit and Banking, 154-171.

Cooper, R. and H. Kempf (2004). Overturning mundell: Fiscal policy in a monetary union. Review of Economic Studies 71(2), 371-396.

Dixit, A. and L. Lambertini (2003). Symbiosis of monetary and fiscal policies in a monetary union. Journal of International Economics 60(2), 235-247.

Doepke, M. and M. Schneider (2006). Inflation and the redistribution of nominal wealth. Journal of Political Economy 114(6), 1069-1097.

Eichengreen, B. (2005). Europe, the euro and the ecb: Monetary success, fiscal failure. Journal of Policy Modeling 27(4), 427-439.

Fuchs, W. and F. Lippi (2006). Monetary Union with Voluntary Participation1. Review of Economic Studies 73(2), 437-457.

Goltsman, M. and G. Pavlov (2011). Communication in cournot oligopoly.

Hauser, C. and H. Hopenhayn (2008). Trading favors: Optimal exchange and forgiveness.

Krogstrup, S. and C. Wyplosz (2010). A common pool theory of supranational deficit ceilings. European Economic Review 54(2), 269-278.

Melumad, N. and T. Shibano (1991). Communication in settings with no transfers. The RAND Journal of Economics, 173-198.

Persson, M., T. Persson, and L. Svensson (1987). Time consistency of fiscal and monetary policy. Econometrica: Journal of the Econometric Society, 1419-1431.

Phelps, E. (1973). Inflation in the theory of public finance. The Swedish Journal of Economics, $67-82$. 
Reinhart, C. and M. Sbrancia (2011). The liquidation of government debt. Technical report, National Bureau of Economic Research.

Roberts, K. (1985). Cartel behaviour and adverse selection. The Journal of Industrial Economics 33(4), 401-413.

Rodden, J. (2006). Hamilton's paradox: the promise and peril of fiscal federalism. Cambridge Univ Pr.

Sims, C. and T. Zha (2006). Were there regime switches in us monetary policy? The American Economic Review 96(1), 54-81.

Thomas, J. and T. Worrall (1990). Income fluctuation and asymmetric information: An example of a repeated principal-agent problem*1. Journal of Economic Theory 51(2), 367390.

Velasco, A. (2000). Debts and deficits with fragmented fiscal policymaking. Journal of Public Economics 76(1), 105-125.

\section{Appendix}

\subsection{Many member countries}

The model also provides a rationale for why policy coordination works best among few member countries. The reason is not the cost of communication (zero in the model) but rather the incident of inefficient redistribution and the degree of 'free-riding'. When there are many participating countries it becomes increasingly costly to reciprocate individual reports of high social cost of taxation with higher inflation throughout the entire monetary union. At the same time, domestic investors bear a smaller fraction of the inflation tax resulting from monetization of an individual country's budget 
deficits. In fact, if the number of member countries covered by the fiscal rule becomes large then domestic fiscal policy should eventually cease to respond to other member countries' shocks.

\subsection{Continuation values}

There are no participation constraints such that continuation values are only constrained by what is technically feasible. ${ }^{19}$ In this section the entire set of Pareto optimal allocations in period two is derived. ${ }^{20}$ To do so we will compute the Pareto frontier $P$ along $v \in[\underline{v}, \bar{v}]$, where now $\underline{v}, \bar{v}$ are no longer given ad-hoc. Rather, $v=\bar{v}$ implies that worker consumption is as high as possible in country two, $c_{2}=w$, while it is as low as possible in country one, $c_{1}=0$. When $v=\underline{v}=P(\bar{v})$ it is the other way around. It follows that $\bar{v}=\left(\mu-\frac{1}{2}\right)$ and $\underline{v}=-\frac{1}{2} w$.

To make notation simpler denote $c_{i}^{j k}=c_{i}\left(\theta_{j}, \theta_{k}\right)$. For use throughout this section let us write out first-order conditions for worker consumption (for given $v$ ).

$$
\begin{array}{cr}
c_{1}^{L L}: & \theta_{L}-\frac{1}{2}-\frac{1}{2} \tau+\left(\theta_{L}-\frac{1}{2}\right) \psi_{1}-\frac{1}{2} \psi_{2} \lesseqgtr 0, \\
c_{1}^{L H}: & \theta_{L}-\frac{1}{2}-\frac{1}{2} \tau+\left(\theta_{L}-\frac{1}{2}\right) \psi_{1}+\frac{1}{2} \psi_{2} \lesseqgtr 0, \\
c_{1}^{H L}: & \theta_{H}-\frac{1}{2}-\frac{1}{2} \tau-\left(\theta_{L}-\frac{1}{2}\right) \psi_{1}-\frac{1}{2} \psi_{2} \lesseqgtr 0, \\
c_{1}^{H H}: & \theta_{H}-\frac{1}{2}-\frac{1}{2} \tau-\left(\theta_{L}-\frac{1}{2}\right) \psi_{1}+\frac{1}{2} \psi_{2} \lesseqgtr 0, \\
c_{2}^{L L}: & -\frac{1}{2}+\left(\theta_{L}-\frac{1}{2}\right) \tau-\frac{1}{2} \psi_{1}+\left(\theta_{L}-\frac{1}{2}\right) \psi_{2} \lesseqgtr 0, \\
c_{2}^{L H}: & -\frac{1}{2}+\left(\theta_{H}-\frac{1}{2}\right) \tau-\frac{1}{2} \psi_{1}-\left(\theta_{L}-\frac{1}{2}\right) \psi_{2} \lesseqgtr 0, \\
c_{2}^{H L}: & -\frac{1}{2}+\left(\theta_{L}-\frac{1}{2}\right) \tau+\frac{1}{2} \psi_{1}+\left(\theta_{L}+\frac{1}{2}\right) \psi_{2} \lesseqgtr 0, \\
c_{2}^{H H}: & -\frac{1}{2}+\left(\theta_{H}-\frac{1}{2}\right) \tau+\frac{1}{2} \psi_{1}-\left(\theta_{L}-\frac{1}{2}\right) \psi_{2} \lesseqgtr 0,
\end{array}
$$

\footnotetext{
${ }^{19}$ In the simple model studied, the First Best would be achieved by monetary unions of unit membership. "Leaving the monetary union" is thus not considered a possible alternative policy. See Fuchs and Lippi (2006) for a model that features a non-trivial trade-off between staying in and leaving a monetary union.

${ }^{20}$ This is for completeness' sake. No new insights are gained and the main result of the paper (theorem 4) is not affected by this increase in generality.
} 
where $\tau$ is the Lagrange multiplier on the promise-keeping constraint for agent two and $\psi_{i}$ is the multiplier on the incentive compatibility constraint for agent $i=1,2$. We will compute the optimal allocation for $v \in\left[\underline{v}, v_{0}\right]$, where the case $v \in\left[v_{0}, \bar{v}\right]$ follows from symmetry. $P$ will be piece-wise linear with kinks $\underline{v}_{j}, j=1,2,3,4$, and $\underline{v}^{\prime}<\underline{v}_{4}<\underline{v}_{3}<\underline{v}_{2}<\underline{v}_{1}<v_{0}$.

\subsubsection{Region I: $v \in\left[\underline{v}_{1}, v_{0}\right]$}

$c_{1}^{L H}, c_{1}^{H L}, c_{2}^{L H}$ take interior values such that (21), (22), and (25) hold with equality. The remaining firstorder conditions yield corner solutions $c_{1}^{L L}=c_{2}^{L L}=c_{2}^{H L}=0$ and $c_{1}^{H H}=c_{2}^{H H}=w$. Both incentive compatibility constraints bind such that multipliers are given by

$$
\tau=2 \mu-1, \quad \psi_{1}=\frac{\sigma^{2}-\mu(1-\mu)}{(\mu-\sigma)(1-\mu+\sigma)}, \quad \psi_{2}=\frac{(2 \mu-1)\left(\sigma^{2}+\mu(1-\mu)\right)}{(\mu-\sigma)(1-\mu+\sigma)} .
$$

Note that $\psi_{1}$ is strictly positive if preference shocks have high mean and dispersion (see definition 2). The interior policies for a given $v \in\left[\underline{v}_{1}, v_{0}\right]$ are

$$
c_{1}^{L H}=4\left(v_{0}-v\right), \quad c_{1}^{H L}=\frac{1-\mu+\sigma}{\mu-\sigma}+4\left(v_{0}-v\right), \quad c_{2}^{L H}=\frac{1-\mu+\sigma}{\mu-\sigma} .
$$

We have $c_{1}^{H L}=w$ at $v=\underline{v}_{1}$ where

$$
\underline{v}_{1}=\frac{3 \sigma-\mu}{4(\mu-\sigma)} w
$$

\subsubsection{Region II: $v \in\left[\underline{v}_{2}, \underline{v}_{1}\right]$}

$c_{1}^{L H}, c_{2}^{L H}$ take interior values such that (21), and (25) hold with equality. The remaining first-order conditions yield corner solutions $c_{1}^{L L}=c_{2}^{L L}=c_{2}^{H L}=0$ and $c_{1}^{H L}=c_{1}^{H H}=c_{2}^{H H}=w$. Only the second country's compatibility constraint binds such that multipliers are given by

$$
\tau=\frac{1-\mu+\sigma}{\mu+\sigma-1}\left(1-\frac{\sigma^{2}-\mu(1-\mu)}{\sigma}\right), \quad \psi_{2}=\frac{\sigma^{2}-\mu(1-\mu)}{\sigma} .
$$


The interior policies for a given $v \in\left[\underline{v}_{2}, \underline{v}_{1}\right]$ are

$$
c_{1}^{L H}=(2(\mu-\sigma)-1) \frac{4 v+w}{2 \sigma}, \quad c_{2}^{L H}=\frac{4 v+(1-2 \sigma) w}{2 \sigma} .
$$

Note that both are decreasing as $v$ decreases - however, $c_{1}^{L H}>0$ throughout region II such that country one will still retaliate. We have $c_{2}^{L H}=0$ at $v=\underline{v}_{2}$ where

$$
\underline{v}_{2}=-\frac{1-2 \sigma}{4} w
$$

\subsubsection{Region III: $v \in\left[\underline{v}_{3}, \underline{v}_{2}\right]$}

$c_{1}^{L H}, c_{2}^{H H}$ take interior values such that (21), and (27) hold with equality. The remaining first-order conditions yield corner solutions $c_{1}^{L L}=c_{2}^{L L}=c_{2}^{L H}=c_{2}^{H L}=0$ and $c_{1}^{H L}=c_{1}^{H H}=w$. Only the second country's compatibility constraint binds such that multipliers are again given by

$$
\tau=\frac{1-\mu+\sigma}{\mu+\sigma-1}\left(1-\frac{\sigma^{2}-\mu(1-\mu)}{\sigma}\right), \quad \psi_{2}=\frac{\sigma^{2}-\mu(1-\mu)}{\sigma} .
$$

The interior policies for a given $v \in\left[\underline{v}_{3}, \underline{v}_{2}\right]$ are

$$
c_{1}^{L H}=(2(\mu-\sigma)-1) \frac{4 v+w}{2 \sigma}, \quad c_{2}^{H H}=\frac{4 v+w}{2 \sigma} .
$$

Note that both are decreasing as $v$ decreases - however, $c_{1}^{L H}>0$ throughout region II such that country one will still retaliate. We have that the incentive compatibility constraint for country one starts binding at $v=\underline{v}_{3}$ where

$$
\underline{v}_{3}=-\left[\frac{1}{4}-\frac{\sigma(2(\mu-\sigma)-1)}{(2(\mu-\sigma)-1)^{2}+2}\right] w
$$




\subsubsection{Region IV: $v \in\left[\underline{v}_{4}, \underline{v}_{3}\right]$}

$c_{1}^{L H}, c_{2}^{H H}$ take interior values such that (21), and (27) hold with equality. The remaining first-order conditions yield corner solutions $c_{1}^{L L}=c_{2}^{L L}=c_{2}^{L H}=c_{2}^{H L}=0$ and $c_{1}^{H L}=c_{1}^{H H}=w$. Only the first country's compatibility constraint binds such that multipliers are given by

$$
\tau=\frac{2(\mu-\sigma)-1}{1-2\left(\sigma^{2}+\mu(1-\mu)\right)}, \quad \psi_{1}=\frac{2\left(\sigma^{2}+\mu(1-\mu)\right)}{1-2\left(\sigma^{2}+\mu(1-\mu)\right)} .
$$

The interior policies for a given $v \in\left[\underline{v}_{4}, \underline{v}_{3}\right]$ are

$$
c_{1}^{L H}=\frac{-\left(1-2\left(\sigma^{2}+\mu(1-\mu)\right)\right) w-2 v}{\sigma^{2}+\mu(1-\mu)}, \quad c_{2}^{H H}=(2(\mu-\sigma)-1) \frac{w+2 v}{\sigma^{2}+\mu(1-\mu)} .
$$

We have that $c_{1}^{L H}=w$ at $v=\underline{v}_{4}$ where

$$
\underline{v}_{4}=-\frac{1-\left(\sigma^{2}+\mu(1-\mu)\right)}{2} w
$$

\subsubsection{Region V: $v \in\left[\underline{v} \underline{v}_{4}\right]$}

$c_{1}^{L L}, c_{2}^{H H}$ take interior values such that (20), and (27) hold with equality. The remaining first-order conditions yield corner solutions $c_{2}^{L L}=c_{2}^{L H}=c_{2}^{H L}=0$ and $c_{1}^{L H}=c_{1}^{H L}=c_{1}^{H H}=w$. Only the first country's compatibility constraint binds such that multipliers are again given by

$$
\tau=\frac{2(\mu-\sigma)-1}{1-2\left(\sigma^{2}+\mu(1-\mu)\right)}, \quad \psi_{1}=\frac{2\left(\sigma^{2}+\mu(1-\mu)\right)}{1-2\left(\sigma^{2}+\mu(1-\mu)\right)} .
$$

The interior policies for a given $v \in\left[\underline{v}, \underline{v}_{4}\right]$ are

$$
c_{1}^{L L}=\frac{-4 v-\left(1+2\left(\sigma^{2}+\mu(1-\mu)\right)\right) w}{1-2\left(\sigma^{2}+\mu(1-\mu)\right)}, \quad c_{2}^{H H}=(2(\mu-\sigma)-1) \frac{4 v+2 w}{1-2\left(\sigma^{2}+\mu(1-\mu)\right)} .
$$

We have that $c_{1}^{L L}=w$ and $c_{2}^{H H}=0$ at $v=\underline{v}$.

How would theorem 3 change if we allow continuation values to be lower than $\underline{v}_{1}$ (higher than 
$\left.P\left(\underline{v}_{1}\right)\right)$ ? First period flexibility will be increased: $c_{1}^{H L}$ and $c_{2}^{L H}$ will increase in period one. Note that theorem 4 goes through unchanged, any deviation from symmetric values gives rise to retaliatory fiscal policies. In the main part of the paper I restricted attention to continuation values $v \in\left[\underline{v}_{1}, v_{0}\right]$.

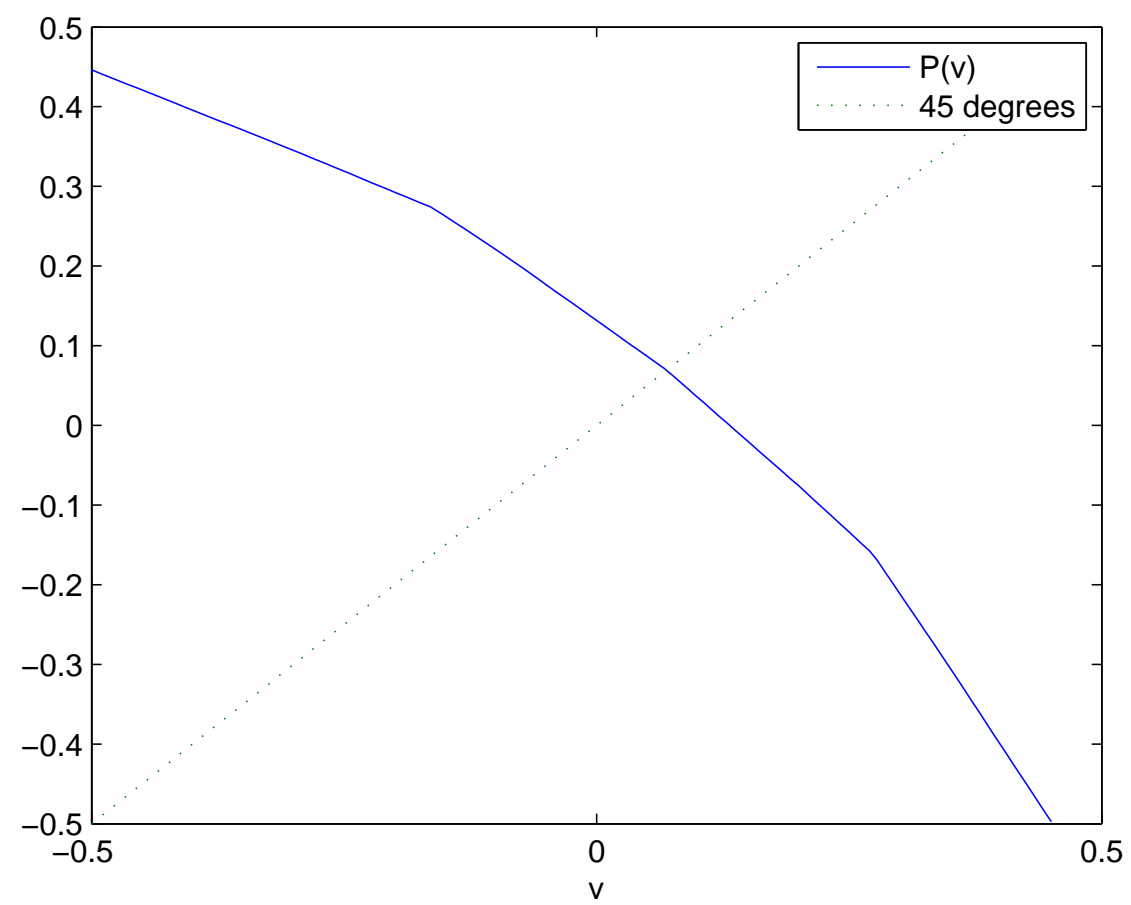

Figure 2: The Pareto frontier $P(v)$ intersects the 45 degree line at $v=v_{0}$. This numerical example assumes high mean and dispersion of preference shocks, $\theta_{L}=0.71$ and $\theta_{H}=1.19$, and normalizes $w=1$.

\subsection{Proofs}

Proof of Lemma 1. This is immediate from the assumption that $\theta_{L}<1<\theta_{H}$.

Proof of Theorem 1. It is readily verified that a fiscal rule of the form

$$
c_{j}\left(s_{1}, s_{2}\right)= \begin{cases}w, & \text { if } s_{1}=s_{2}=s_{H} \\ 0, & \text { else. }\end{cases}
$$

is incentive compatible. The slack in the incentive compatibility constraints can then be used to improve allocative efficiency in one of the two following ways: (i) choose interior values for $c_{1}\left(s_{H}, s_{L}\right)$ 


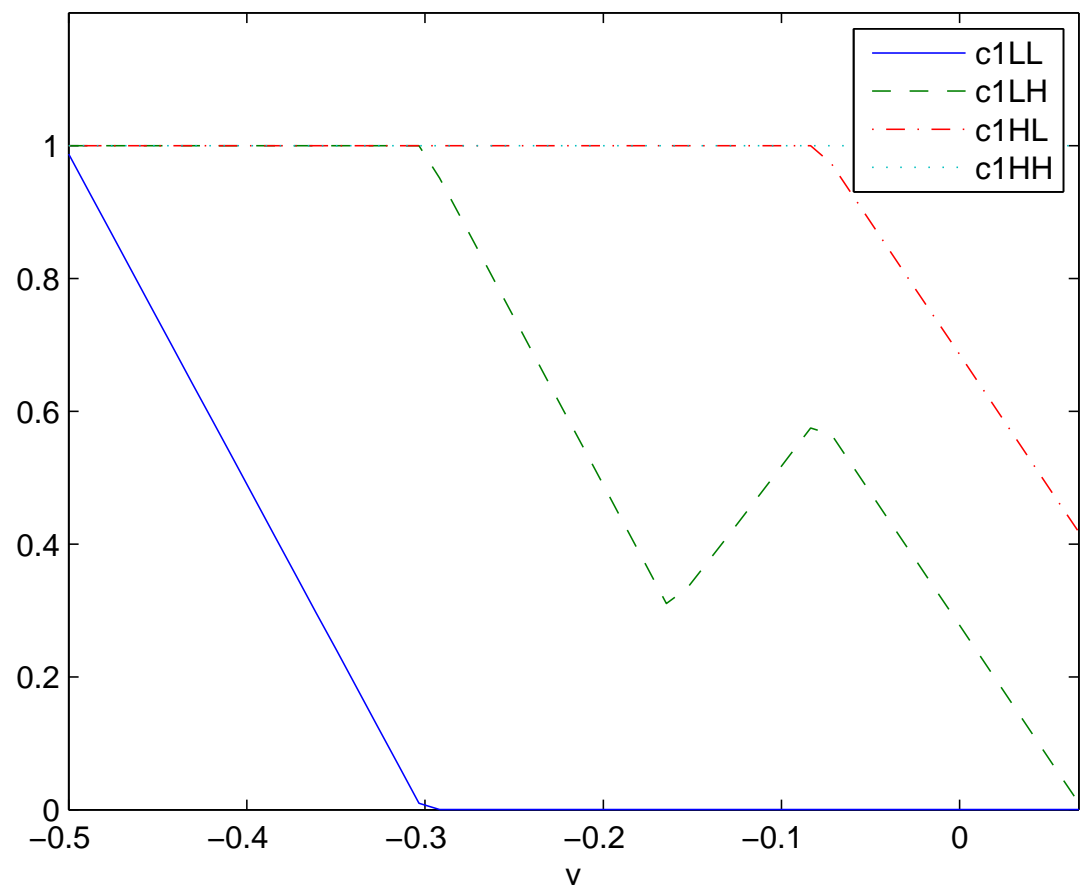

Figure 3: Worker consumption in country one for $v \leq v_{0}$.

and $c_{2}\left(s_{L}, s_{H}\right)$, or (ii) make $c_{1}\left(s_{H}, s_{L}\right)=c_{2}\left(s_{L}, s_{H}\right)=w$ incentive compatible by choosing interior values for $c_{1}\left(s_{L}, s_{H}\right)$ and $c_{2}\left(s_{H}, s_{L}\right)$. It is then easy to check that (i) leads to strictly higher joint welfare than (ii) if and only if $\mu<1$.

Proof of Theorem 2. A decrease in $v$ should lead to an increase in $P(v)$ such that workers in country one should consume more on average. When $c_{1}\left(s_{H}, s_{L}\right)$ increases this increases the righthand side of country one's incentive compatibility constraint and decreases the lefthand sice of country two's incentive compatibility constraint. But both were already binding at $v=v_{0}$. The monetary authority has two possible ways to restore incentive compatibility: (i) decrease $c_{2}\left(s_{L}, s_{H}\right)$, or (ii) allow for $c_{1}\left(s_{L}, s_{H}\right)>0$. In case (i) only country two's incentive compatibility constraint binds and the derivative of $P(v)$ from the left at $v_{0}$ is $\frac{2 \theta_{H} \theta_{L}}{2 \mu-1}-1$. In case (ii), both incentive compatibility constraints bind and the derivative of the function $P(v)$ from the left at $v_{0}$ is $2 \mu-1$. Case (ii) will then yield a higher value for $P(v)$ for $v<v_{0}$ if

$$
2 \mu-1>\frac{2 \theta_{H} \theta_{L}}{2 \mu-1}-1
$$




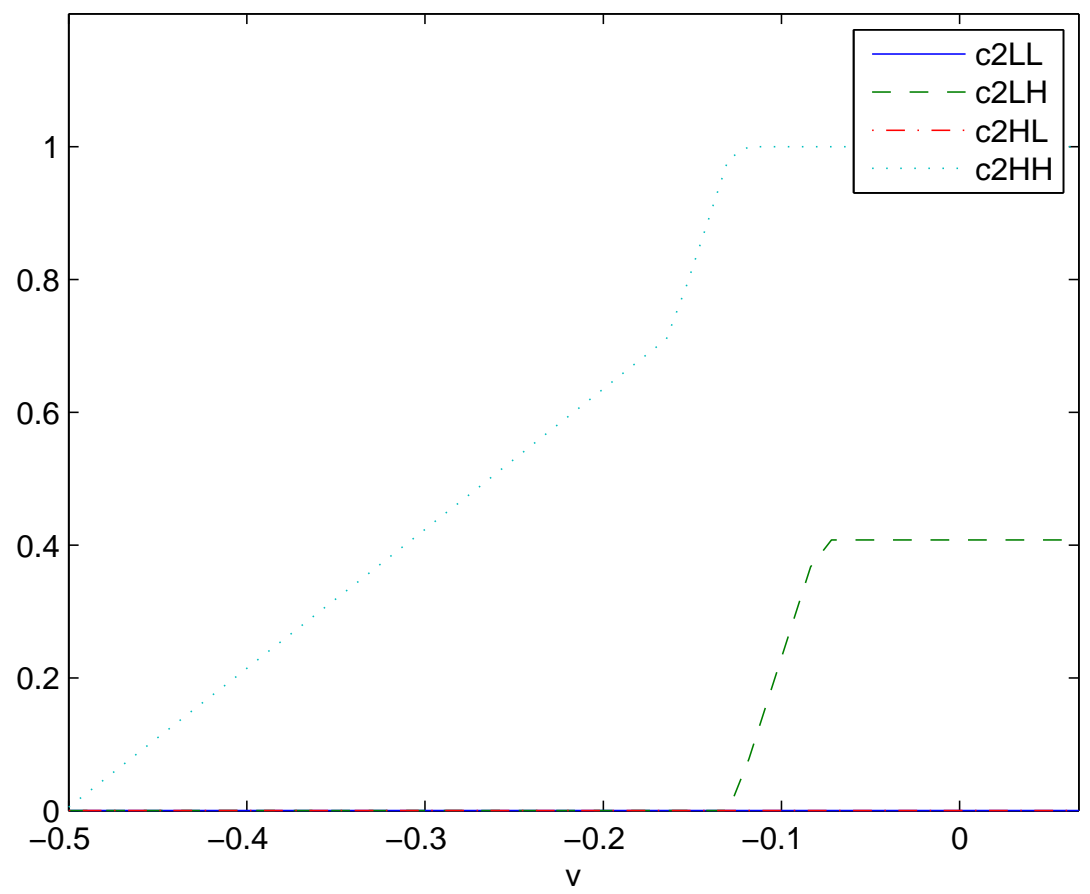

Figure 4: Worker consumption in country two for $v \leq v_{0}$.

which simplifies to the condition $\sigma>\sqrt{\mu(1-\mu)} \cdot \underline{v}_{1}$ is defined as the value of $v$ such that $c_{1}\left(s_{H}, s_{L}\right)=$ $w$ under case (ii).

Alternatively, one can write the problem in Lagrangian form and check the relevant multipliers. Specifically, for case (i) one has to verify that the non-negativity constraint on $c_{1}\left(s_{L}, s_{H}\right)$ binds. This is the case for $\sigma<\sqrt{\mu(1-\mu)}$. For case (ii) we have to check that the multiplier on the incentive compatibility constraint of country one is positive, which is the case if $\sigma>\sqrt{\mu(1-\mu)}$.

Proof of Theorem 3. We will verify that continuation values will be used to make first period worker consumption more responsive to domestic shocks. We also conjecture that equal reports, $s_{1}=s_{2}$, yield continuation values of $v_{0}$ each. Note that $P$ is piecewise linear with slope $-(2 \mu-1)$ for $v<v_{0}$ and slope $-\frac{1}{2 \mu-1}$ for $v>v_{0}$. It can be shown that

$$
P\left(\underline{v}_{1}\right)-\underline{v}_{1}=\left(1-\frac{1}{2(\mu-\sigma)}\right) \mu w<\frac{2(\mu-\sigma)-1}{\delta} w .
$$

Setting $v_{1}\left(s_{L}, s_{H}\right)-v_{1}\left(s_{H}, s_{L}\right)=P\left(\underline{v}_{1}\right)-\underline{v}_{1}$ in the incentive compatibility constraint we can solve for 
$c_{1}\left(s_{H}, s_{L}\right)<w$. Let $\psi$ be the multiplier on the incentive compatibility constraint of either country (symmetry!), then the condition for optimality of $c_{1}\left(s_{H}, s_{L}\right)$ yields $\psi=\frac{\mu+\sigma-1}{\mu-\sigma}$ (recall that $\mu+\sigma=$ $\left.\theta_{H}>1\right)$. Then the marginal benefit from increasing $c_{1}\left(s_{L}, s_{L}\right)$ is $\theta_{L}-1-\psi \theta_{L}<0$ and the marginal benefit from increasing $c_{1}\left(s_{L}, s_{H}\right)$ is $\theta_{L}-1+\psi \theta_{L}<0$. Hence $c_{1}\left(s_{L}, s_{L}\right)=c_{1}\left(s_{L}, s_{H}\right)=0$. The marginal benefit from increasing $c_{1}\left(s_{H}, s_{H}\right)$ is $\theta_{H}-1+\left(1-\theta_{L}\right) \psi>0$, and hence $c_{1}\left(s_{H}, s_{H}\right)=w$.

Let $\chi^{k l}$ be the multipliers on constraints $v_{1}\left(s_{l}, s_{k}\right) \leq P\left(v_{2}\left(s_{l}, k\right)\right)$, for $l, k=L, H$, and recall that by symmetry $v_{1}\left(s_{l}, s_{k}\right)=v_{2}\left(s_{k}, s_{l}\right)$. First, note that the monetary authority would prefer to increase $v_{1}\left(s_{L}, s_{L}\right)$ until $\chi^{L L}>0$ such that, by symmetry, $v_{1}\left(s_{L}, s_{L}\right)=v_{2}\left(s_{L}, s_{L}\right)=v_{0}$. Second, note that $v_{1}\left(s_{H}, s_{H}\right)<v_{0}$ would imply $v_{2}\left(s_{H}, s_{H}\right)<v_{0}$ by symmetry and hence $\chi^{H H}=0$. Then the marginal benefit from increasing $v_{1}\left(s_{H}, s_{H}\right)$ would be $1-\psi>0$. But then we should set $v_{1}\left(s_{H}, s_{H}\right)=v_{2}\left(s_{H}, s_{H}\right)=v_{0}$. Third, consider continuation values when countries experience different shocks. When $v_{2}\left(s_{H}, s_{L}\right)>v_{0}$ then its optimality condition yields

$$
1+\psi-\chi^{H L}+\chi^{L H} P^{\prime}\left(v_{2}\left(s_{H}, s_{L}\right)\right)=1+\psi-\chi^{H L}-\chi^{L H} \frac{1}{2 \mu-1}=0
$$

To verify that $v_{2}\left(s_{L}, s_{H}\right)<v_{0}$ is at a corner, note that that its marginal benefit is given by

$$
1-\psi-\chi^{L H}+\chi^{H L} P^{\prime}\left(v_{2}\left(s_{L}, s_{H}\right)\right)=1-\psi-\chi^{L H}-\left[1+\psi-\chi^{L H} \frac{1}{2 \mu-1}\right](2 \mu-1)
$$

which is negative if $2 \mu(1-\mu)<\sigma$. Since $\sigma>\sqrt{\mu(1-\mu)}>2 \mu(1-\mu)$ it is indeed optimal to vary continuation values whenever reports about domestic conditions differ across countries. 